\title{
Vineyard pruning waste as an alternative carbon source to produce novel biosurfactants by Lactobacillus paracasei
}

\author{
X. Vecino ${ }^{\mathrm{a}, \mathrm{b}, *}$, L. Rodríguez-López ${ }^{\mathrm{b}}$, E.J. Gudiña ${ }^{\mathrm{a}}$, J.M. Cruz ${ }^{\mathrm{b}}$, A.B. Moldes ${ }^{\mathrm{b}}$, L.R. Rodrigues ${ }^{\mathrm{a}}$ \\ ${ }^{a}$ CEB-Centre of Biological Engineering, University of Minho, 4710-057 Braga, Portugal \\ ${ }^{\mathrm{b}}$ Chemical Engineering Department, School of Industrial Engineering (EEI), University of Vigo, Campus As Lagoas-Marcosende, 36310 Vigo-Pontevedra, Spain
}

\section{A R T I C L E I N F O}

\section{Article history:}

Received 30 March 2017

Received in revised form 15 May 2017

Accepted 5 June 2017

Available online 15 June 2017

\section{Keywords:}

Vineyard pruning waste

Cellulosic sugars

Biosurfactant

Lactobacillus paracasei

Chemical composition

\author{
A B S T R A C T
}

Cellulosic sugars extracted from vineyard pruning waste (VPW) were used as a low-cost carbon source for biosurfactant production by Lactobacillus paracasei. The results obtained showed that when glucose from VPW was used, the biosurfactant was a glycolipopeptide, whereas when it was replaced by lactose the biosurfactant produced was a glycoprotein. Additionally, it was found that the extraction process, either with phosphate-buffer or phosphate-buffer saline, influenced the biosurfactant chemical structure and emulsion capacity. Overall, these results highlight the possibility of producing biosurfactants "à la carte" with the same strain but changing the carbon source, increasing its potential in different industrial applications.

(c) 2017 The Korean Society of Industrial and Engineering Chemistry. Published by Elsevier B.V. All rights reserved.

\section{Introduction}

The valorization of agricultural wastes, following the European Directive 2008/98/EC, is focused on the whole waste recycling, from generation to disposal, emphasizing their recovery and recycling. As a result, economic, environmental and social benefits increase at the same time as the industrial resource efficiency is enhanced.

VPW is the residue after pruning the vineyard trees, such as thin and thick branches, that is usually burned by the small winery producers, contributing to global warming by the emission of greenhouse gases like $\mathrm{CO}_{2}$ during their combustion [1,2]. VPW is a renewable, abundant and attractive carbon source composed by cellulose, hemicellulose and lignin. Therefore, this lignocellulosic waste can be used as a low-cost feedstock in several biotechnological processes.

In 2012, World vineyard cultivation reached a total surface of 7487 thousands of hectares (kha), being Spain the country with the highest expansion of planted surface areas ( $1017 \mathrm{kha}$ areas), followed by France, China and Italy with 792 kha, 706 kha and $705 \mathrm{kha}$, respectively. Regarding the Europe vineyard cultivation, Europe accounts half of the vine-growing area (about 55\%),

\footnotetext{
* Corresponding author at: CEB-Centre of Biological Engineering, University of Minho, 4710-057 Braga, Portugal.

E-mail addresses: xanel.vecino@ceb.uminho.pt, xanel.vecino@uvigo.es (X. Vecino).
}

followed by Asia (24\%), America (14\%), Africa (5\%) and Oceania (3\%) [3].

Usually autohydrolysis-posthydrolysis or prehydrolysis (acid hydrolysis) treatments are employed to obtain hemicellulosic sugars (mainly glucose and xylose) from lignocellulosic residues. Several researchers evaluated the use these hydrolysates to produce biosurfactants [1,4-8], lactic acid [4,6,9-11], xylitol [1214], antioxidants [15], as well as phenyllactic acid [16]. However, the cellulosic fraction obtained after the hydrolysis treatments remains as by-product, probably because its use involves a saccharification process using acids or enzymes. Therefore, Bustos et al. [17] proposed a delignification stage of VPW, followed by an enzymatic hydrolysis treatment, to obtain glucose solutions that can be used as carbon source in culture media (in this case to produce lactic acid by Lactobacillus rhamnosus). More recently, Vecino et al. $[18,19]$ evaluated the applicability of the cellulosic fraction from VPW as an adsorbent to remove micronutrients and dyes from winery wastewater.

On the other hand, biosurfactants are promising molecules as potential alternatives to their chemical counterparts [20]. These molecules are surface-active compounds of microbial origin with well-known advantages and novel applications in the pharmaceutical, cosmetic and environmental industries [21-23]. However, their high production and recovery costs have limited their scaleup to industrial set-ups. Therefore, in order to bypass this limitation, considerable efforts have been conducted in the last years to use renewable agro-industrial substrates as cost-effective alternative substrates for their production [24,25]. 
Based on the above discussion, a sustainable biotechnological process using cellulosic sugars from VPW as carbon source to obtain biosurfactants from $L$. paracasei was herein developed. The effect of the carbon source and the extraction process on the biosurfactant production was studied. Furthermore, the biosurfactants were characterized regarding their critical micelle concentration, emulsification capacity and chemical composition, including elemental analysis, carbohydrates, protein and lipids contents, fatty acid profile and Fourier transform infrared spectroscopy.

\section{Materials and methods}

\section{Strain and culture conditions}

L. paracasei ssp. paracasei A20, isolated from a Portuguese dairy industry and previously reported as biosurfactant producer [26], was used in this study. The bacterial strain was grown in MRS (de Man, Rogosa and Sharpe) agar plates at $37^{\circ} \mathrm{C}$ for $24 \mathrm{~h}$. Pre-cultures were prepared by solubilizing all the cells from a plate with $5 \mathrm{~mL}$ of the appropriate culture medium, that were subsequently transferred to $250 \mathrm{~mL}$ Erlenmeyer flasks containing the same culture medium, to make a final volume of $100 \mathrm{~mL}$. Subsequently, the flasks were incubated at $37^{\circ} \mathrm{C}$ and $150 \mathrm{rpm}$ during $24 \mathrm{~h}$.

\section{Characterization of vineyard pruning waste}

VPW was obtained from a Spanish local wine industry in Galicia, located in the Northwest of Spain. The lignocellulosic residue was dried, milled to $<1 \mathrm{~mm}$, homogenized into a single lot to avoid differences in the composition along the work, and stored at room temperature in a dark and dry place until use. The characterization of VPW was carried out by quantitative hydrolysis in a two-stage acid treatment, following the methodology previously reported [27]. The first stage was carried out with sulfuric acid $(72 \% \mathrm{w} / \mathrm{w})$ at $30^{\circ} \mathrm{C}$ for $1 \mathrm{~h}$, whereas the second stage was carried out with sulfuric acid ( $3 \% \mathrm{w} / \mathrm{w})$ at $121^{\circ} \mathrm{C}$ for $1 \mathrm{~h}$. The solid residue after hydrolysis was considered as Klason lignin. Hydrolysates were analyzed by HPLC (Agilent Technologies 1200 Series, Germany) using Rezex RHM Monosaccharide H+ (8\%) column (Phenomenex, USA) maintained at a constant temperature of $65^{\circ} \mathrm{C}$ (mobile phase $0.01 \mathrm{M} \mathrm{H}_{2} \mathrm{SO}_{4}$, flow rate $0.4 \mathrm{~mL} \mathrm{~min}^{-1}$, IR and UV detection). This method allows the direct determination of sugars in the solid fraction. The composition of solid fractions solids was expressed as VPW dry weight (w/w).

\section{a) Extraction of the cellulosic fraction}

In order to remove the hemicellulosic sugars, VPW was hydrolyzed following the methodology proposed by Bustos et al. [9]: $3 \% \mathrm{H}_{2} \mathrm{SO}_{4} ; 15 \mathrm{~min}$ at $130^{\circ} \mathrm{C}$; liquid-solid ratio $8: 1(\mathrm{w} / \mathrm{w})$. After that, the solid fraction (consisting of lignin and cellulose) was subjected to a delignification process following the methodology proposed by Bustos et al. [17] with slight modifications: $6.5 \%$ $\mathrm{NaOH} ; 60 \mathrm{~min}$ at $130^{\circ} \mathrm{C}$; liquid-solid ratio $10: 1(\mathrm{w} / \mathrm{w})$. The solid residue (cellulosic fraction) resulting from this treatment was separated by filtration, washed with demineralized water and air dried for enzymatic hydrolysis.

\section{b) Enzymatic hydrolysis of the cellulosic fraction}

The cellulosic fraction obtained from the alkali delignification treatment was subjected to enzymatic hydrolysis with commercial enzyme concentrates (cellulase and $\beta$-glucosidase) provided by Novozymes (Denmark). Cellulase activity in the hydrolysates was assayed through the filter paper activity test (FPA) according to
Mandels et al. [28], and was expressed as filter paper units (FPU) per $\mathrm{mL}$. The $\beta$-glucosidase activity was measured according to Paquot and Thonart [29]. The operational conditions used for the enzymatic hydrolysis were as follows: $48.5^{\circ} \mathrm{C}, \mathrm{pH} 4.85,48 \mathrm{~h}$, liquor-solid ratio 15:1 (w/w). Regarding the cellulase activity, a cellulase-substrate ratio of $28 \mathrm{FPU} / \mathrm{g}$ of cellulose was used, supplemented with cellobiase at a cellobiase-cellulase ratio of $13 \mathrm{IU} / \mathrm{FPU}$ (during the enzymatic hydrolysis, cellobiase was added to avoid the accumulation of cellobiose in the medium, which could inhibit the cellulase activity).

Fig. 1 shows the flowchart proposed for the chemicalbiotechnological processing of different fractions from VPW that were used in this study.

Biosurfactant production by L. paracasei using glucose from VPW as carbon source

The glucose-based medium (containing $33 \mathrm{~g} / \mathrm{L}$ glucose) obtained after enzymatic hydrolysis was supplemented with $10 \mathrm{~g} / \mathrm{L}$ of yeast extract (YE) and $10 \mathrm{~g} / \mathrm{L}$ of corn steep liquor (CSL) as nitrogen sources; subsequently, it was sterilized at $121^{\circ} \mathrm{C}$ for $15 \mathrm{~min}$ and used directly as culture medium. Fermentations were performed in a $2 \mathrm{~L}$ Applikon fermentor, with a working volume of

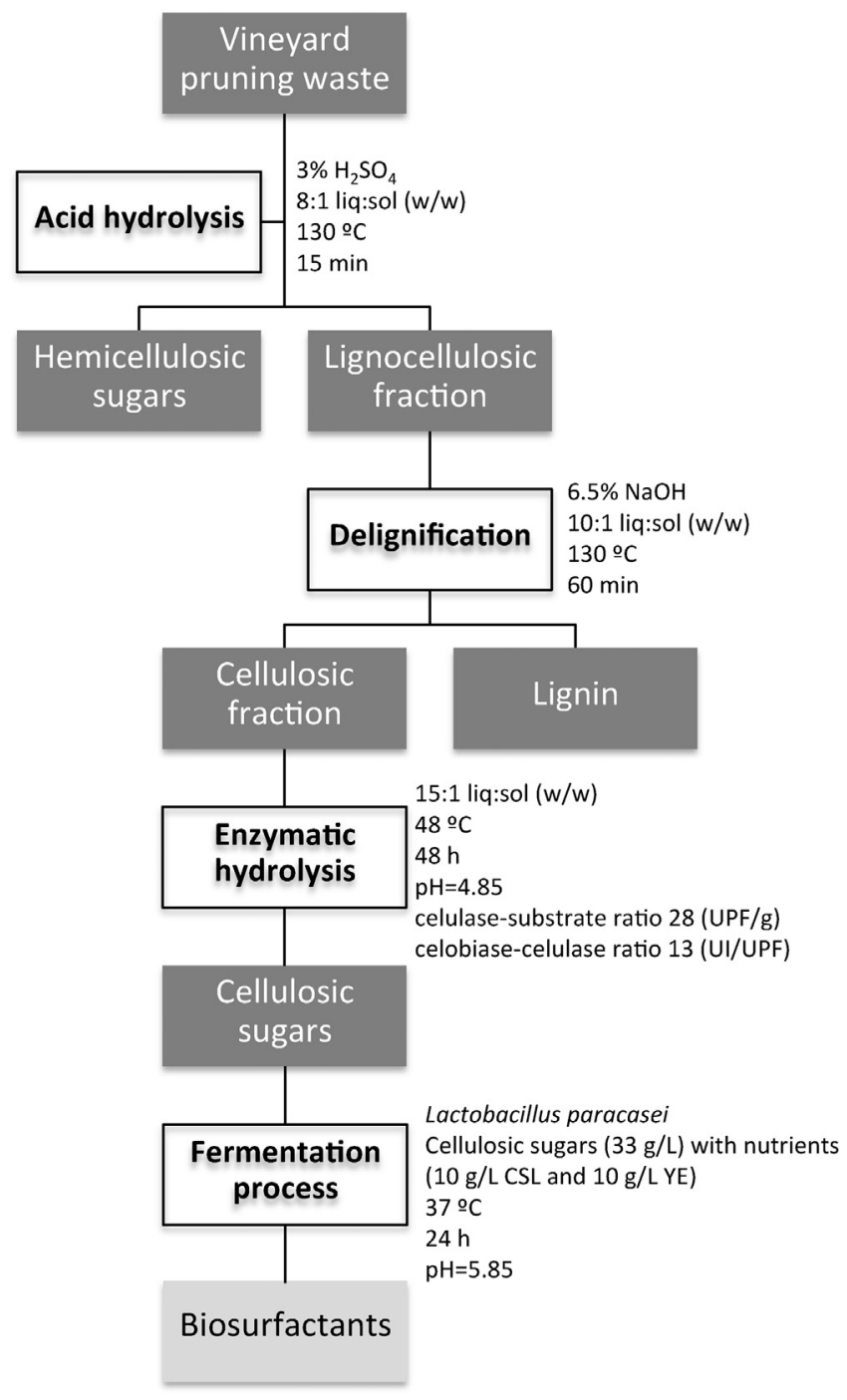

Fig. 1. Methodology used for the full valorization of vineyard pruning waste. 
$1.5 \mathrm{~L}$, at $37^{\circ} \mathrm{C}$ and $200 \mathrm{rpm}$ for $24 \mathrm{~h}$. The $\mathrm{pH}$ was adjusted to 5.85 along the fermentation by automatic addition of $\mathrm{NaOH} 4 \mathrm{M}$.

Biosurfactant production by L. paracasei using lactose as carbon source

For comparative purposes, a culture medium where glucose from VPW was replaced by synthetic lactose was used. The lactosebased medium contained $33 \mathrm{~g} / \mathrm{L}$ of lactose, $10 \mathrm{~g} / \mathrm{L}$ of YE and $10 \mathrm{~g} / \mathrm{L}$ of CSL. Fermentations with this culture medium were performed using the same operational conditions described above.

\section{Study of biosurfactant production}

Biosurfactants can be excreted to the culture medium (extracellular biosurfactants) or remain attached to the cell wall (cell-bound biosurfactants). The $L$. paracasei strain used in this work has been reported to produce mainly cell-bound biosurfactants [30]. Nevertheless, the production of both types of biosurfactant was herein evaluated.

\section{a) Extracellular biosurfactants}

The surface tension (ST) of samples taken at different time points, during the fermentation, was measured and compared to the initial ST of the culture medium. As the ST of the culture medium is very close to the minimum ST value achieved in the presence of the biosurfactants produced by $L$. paracasei, the samples were diluted 4 (dilution factor $(\mathrm{DF}=4)$ ) and $16(\mathrm{DF}=16)$ times in order to detect any extracellular biosurfactant production. The ST measurements were performed according to the Wilhelmy plate method using an Easy Dyne K20 Tensiometer (KRÜSS GmbH, Germany) equipped with a platinum plate.

\section{b) Cell-bound biosurfactants}

Cells were harvested by centrifugation ( $9000 \mathrm{rpm}, 20 \mathrm{~min}$ ) at the end of the $L$. paracasei fermentations, washed twice with the same volume of demineralized water and resuspended in $250 \mathrm{~mL}$ of

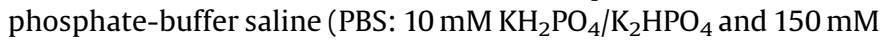

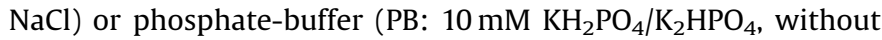
$\mathrm{NaCl}$ ). The ratio of culture medium:buffer solution used for the extraction was 6:1. The extraction with PBS was performed at room temperature $\left(25^{\circ} \mathrm{C}\right)$ and $150 \mathrm{rpm}$ for $2 \mathrm{~h}$ [7], whereas the extraction with $\mathrm{PB}$ was performed at $65^{\circ} \mathrm{C}$ and $150 \mathrm{rpm}$ for $1.5 \mathrm{~h} \mathrm{[31].}$ Afterwards, the cells were removed by centrifugation $(9000 \mathrm{rpm}$, $20 \mathrm{~min}$ ) and the remaining supernatant was filtered through a $0.2 \mu \mathrm{m}$ pore-size filter (Whatman, GE Healthcare, UK). The solution containing the cell-bound biosurfactants was dialyzed against demineralized water at $4{ }^{\circ} \mathrm{C}$ in a Cellu-Sep ${ }^{\odot}$ membrane (molecular weight cut-off 6000-8000 Da; Membrane Filtration Products, Inc., USA) for $48 \mathrm{~h}$. Finally, the biosurfactant extracts were freeze-dried using a lyophilizer CHRIST ${ }^{\circledR}$ Alpha 1-4 LD plus (Germany).

Four different biosurfactant extracts were obtained depending on the carbon source and the methodology used for their extraction, namely biosurfactants produced in glucose-containing medium and extracted with PBS and PB (BS-Glu-PBS and BS-Glu$\mathrm{PB}$, respectively); and biosurfactants produced in lactose-containing medium and extracted with PBS and PB (BS-Lac-PBS and BSLac-PB, respectively).

\section{Characterization of biosurfactants produced by L. paracasei}

\section{a) Critical micelle concentration (CMC)}

CMC is the minimum concentration of biosurfactant needed to produce the maximum reduction in the surface tension of an aqueous solution, being this parameter important in terms of biosurfactant industrial effectiveness and costs. Above the CMC, the ST of a biosurfactant solution remains constant, being that surfactant tension value characteristic for each biosurfactant. On the other hand, below the CMC, the surface tension of biosurfactant solutions varies and a linear relationship between the biosurfactant concentration and the ST is observed. Therefore, the minimum biosurfactant concentration necessary to keep the ST at the minimum value corresponds to its CMC [32]. In order to calculate the CMC of the different biosurfactant extracts obtained in this work, biosurfactant solutions at different concentrations were prepared with demineralized water, and their ST were measured using the Wilhelmy plate method as previously described. The reference ST value of demineralized water was $72 \mathrm{mN} / \mathrm{m}$.

\section{b) Biochemical composition}

The carbohydrate content of the biosurfactant extracts was determined by the phenol-sulfuric acid method [33], using Dglucose as standard. The proteins concentration was calculated by determining the $\mathrm{N}$ content of the extracts. The value of $\mathrm{N}$ was then transformed into protein content multiplying by 6.25 [34]. Elemental analysis was obtained by chromatographic analysis with thermal conductivity detection (TCD). C, N, H and S were determined in a Carlo Erba EA-1108CHNS-O element analyzer.

In addition, the functional groups of the different biosurfactant extracts were determined through Fourier transform infrared spectroscopy (FTIR). Hence, $1 \mathrm{mg}$ of biosurfactant was ground with $10 \mathrm{mg}$ of potassium bromide and pressed $(7500 \mathrm{~kg}$ for $30 \mathrm{~s}$ ) to produce translucent pellets. The FTIR analyses were carried out in a Niocolet 6700 FTIR spectrometer (Thermo Scientific). The spectral measurements were made in the transmittance mode in the range of $400-4000 \mathrm{~cm}^{-1}$, with a resolution of $4 \mathrm{~cm}^{-1}$ and an average of 32 scans. A potassium bromide pellet was used for measuring background absorbance levels.

\section{c) Fatty acid composition determined by GC-MS-MS}

The total lipid content was estimated according to the colorimetric method [35], using cholesterol as standard. Furthermore, the fatty acids profile of the biosurfactant extracts was analyzed by GC-MS-MS (gas chromatography coupled to a mass spectrometer) on a Model Scion 451 GC (Bruker) equipped with a PTV 1019 universal capillary injector, coupled to a mass spectrometer, controlled by System Control software. Prior to analysis, the biosurfactant extracts were submitted to a derivatization process following the procedure described by RodríguezLópez et al. [36]. Afterwards, $1 \mu \mathrm{L}$ of sample was injected using a splitless mode. The fatty acid methyl esters (FAMEs) separation was performed on a DB-WAX column ( $30 \mathrm{~m}$ long, $0.25 \mathrm{~mm}$ i.d., $0.25 \mu \mathrm{m}$ film thickness) using the following oven temperature gradient: $50^{\circ} \mathrm{C}$ for $2 \mathrm{~min}$, then raised to $220^{\circ} \mathrm{C}$ at a rate equal to $4{ }^{\circ} \mathrm{C} \mathrm{min}^{-1}$ and then maintained for more $15 \mathrm{~min}$. Helium was used as carrier gas at a constant flow rate of $1 \mathrm{~mL} \mathrm{~min}^{-1}$. The temperature of both injector inlet and the transfer line of the detector was set at $240^{\circ} \mathrm{C}$.

The mass spectra were obtained using a mass-selective detector under electron impact ionization at a voltage of $70 \mathrm{eV}$ and data were acquired over an $m / z$ range $50-400$. The software used to process the peak areas was MS Data Review (version 8.1).

FAMEs were identified using a mass spectra library supplied with the GC-MS-MS system and by comparison of retention times and mass spectra of a FAME standard mix (Supelco 37 Component FAME Mix: $10 \mathrm{mg} / \mathrm{mL}$ of the FAME reference standard mix in 
methylene chloride, Sigma-Aldrich) injected under the same conditions.

\section{d) Emulsification capacity}

Rosemary oil/water emulsions were formulated using the biosurfactant extracts, BS-Glu-PBS and BS-Glu-PB, as stabilizing agents. For this purpose, $2 \mathrm{~mL}$ of rosemary oil and $2 \mathrm{~mL}$ of biosurfactant solutions were vigorously mixed with a vortex for $2 \mathrm{~min}$. Then, the mixture was allowed to stand for $1 \mathrm{~h}$. Afterwards, the relative emulsion volume (EV,\%) and the emulsion stability (ES, $\%)$ were calculated at different time intervals $(2 \mathrm{~h} ; 1,2,3,7,14$, 21 and 28 days) according the protocol published elsewhere [37]. An emulsion with rosemary oil/demineralized water was used as negative control using the same conditions.

The macro visualizations of the emulsions were obtained $48 \mathrm{~h}$ after the formation of the emulsion with a regular digital camera (Sony optical SteadyShot), using an Optical Zoom $4 \times$ with a $26-\mathrm{mm}$ wide-angle lens and 14.1 Megapixels. Additionally, the emulsion droplets were observed using a Leica DMI 3000B Inverted Microscope equipped with a high-sensitivity camera LEICA DFC450C. The emulsion was placed on the microscope stage and observed through a $20 \times$ objective. Moreover, the droplets were measured (at $20 \pm 2{ }^{\circ} \mathrm{C}$ ) and photographs were taken using the LAS 4.7 software. The size of the droplets was measured 1 month after the formation of the emulsion.

\section{Statistical analysis}

Data are reported as the mean \pm SD (standard deviation) of triplicate determinations. The existence of significant differences among the results was analyzed. One-way analysis of variance (ANOVA) was used followed by the Tukey's HSD test. All statistical tests were performed at a 5\% significance level using the IBM SPSS Statistics 20.0 statistical software package.

\section{Results and discussion}

Several environmentally friendly applications have been proposed for the valorization of VPW as a low-cost feedstock. This residue is composed by $34 \pm 1.42 \%$ cellulose, $19 \pm 1.66 \%$ hemicellulose and $27 \pm 2.80 \%$ lignin. Chemical composition was similar to the VPW reported by other authors probably due to the same origin of VPW [9].

Different treatments applied to VPW in order to obtain hemicellulosic or cellulosic sugars towards the production of added value compounds can be found in the literature. However, most of these applications involve the use of the hemicellulosic fraction rather than the cellulosic sugars. In addition, biosurfactant production by $L$. paracasei using as carbon source the lignocellulosic residue VPW has not been previously reported [1,4-17].

After the hydrolysis of VPW with sulfuric acid two different fractions were obtained, namely a liquid hemicellulosic fraction composed by hemicellulosic sugars (about $18 \mathrm{~g} / \mathrm{L}$ of xylose, $11 \mathrm{~g} / \mathrm{L}$ glucose and $4.5 \mathrm{~g} / \mathrm{L}$ of arabinose) and a solid fraction (that represents about $63 \%$ of the initial residue), that after delignification with $\mathrm{NaOH}$, gave the following composition: $70.7 \pm 0.25 \%$ cellulose, $1.7 \pm 0.06 \%$ hemicelluloses and $25.5 \pm 0.20 \%$ lignin.

The liquid fraction, rich in xylose, was discarded as pentoses are hard to ferment by Lactobacilli strains leading to low fermentation yields; whereas the solid fraction composed basically by cellulose, was subjected to enzymatic saccharification with cellulases and cellobiase. At this stage it is important to use both enzymes to avoid product inhibition of cellobiose on cellulase. After the enzymatic hydrolysis, a liquid medium composed by $33 \pm 0.33 \mathrm{~g} / \mathrm{L}$ of glucose was obtained, which after nutrient supplementation was used to produce biosurfactants by L. paracasei. At this stage the saccharification yield was about $47 \pm 1.63 \%$ (see Fig. 1).

Production of biosurfactants by L. paracasei grown on cellulosic sugars from vineyard pruning waste (VPW)

It is well known that Lactobacillus strains produce cell-bound biosurfactants. However, only few studies evaluated the effect of different carbon sources on the production of biosurfactants by these bacteria [5,30]. Rodrigues et al. [38] suggested that some Lactobacillus strains could alter their biosurfactant production profile (from cell-bound to extracellular biosurfactants) depending on the carbon source used. Therefore, in this work, the ability of $L$. paracasei to produce extracellular biosurfactants was also evaluated. Fig. 2a shows the extracellular biosurfactant production profile of $L$. paracasei using the glucose-based medium obtained from VPW as carbon source. It can be observed that, a slight decrease in the ST of the culture medium was found at the first $8 \mathrm{~h}$ of fermentation. Afterwards, the ST remained almost constant until the end of the fermentation $(24 \mathrm{~h})$. However, that small variation in the ST of the culture medium $(4 \mathrm{mN} / \mathrm{m})$ is not enough to consider the presence of extracellular biosurfactants. Regarding the results obtained using the lactose-based medium; a similar profile was observed (Fig. 2b). The ST of the culture medium was reduced about $4 \mathrm{mN} / \mathrm{m}$ in the first $4 \mathrm{~h}$, which likewise is not enough to consider that the strain produces extracellular biosurfactants.

Regarding the production of cell-bound biosurfactants by $L$. paracasei grown on glucose from VPW, Fig. 3 shows the CMC values

a)

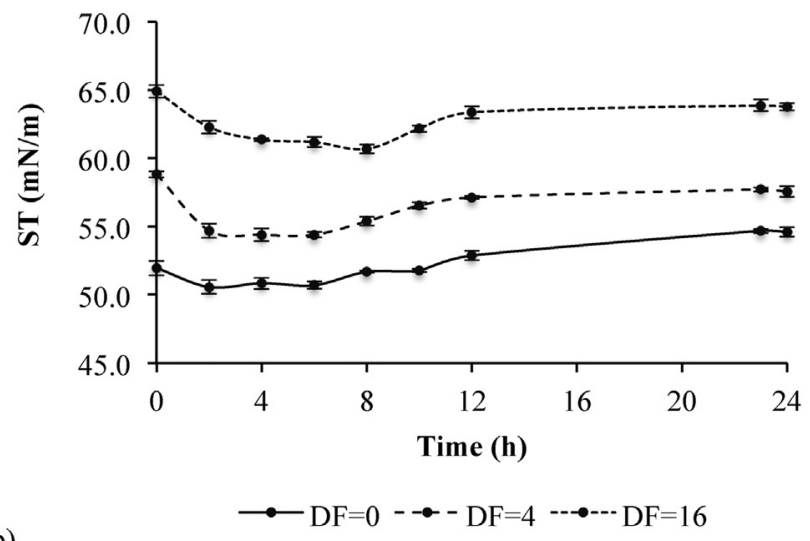

b)

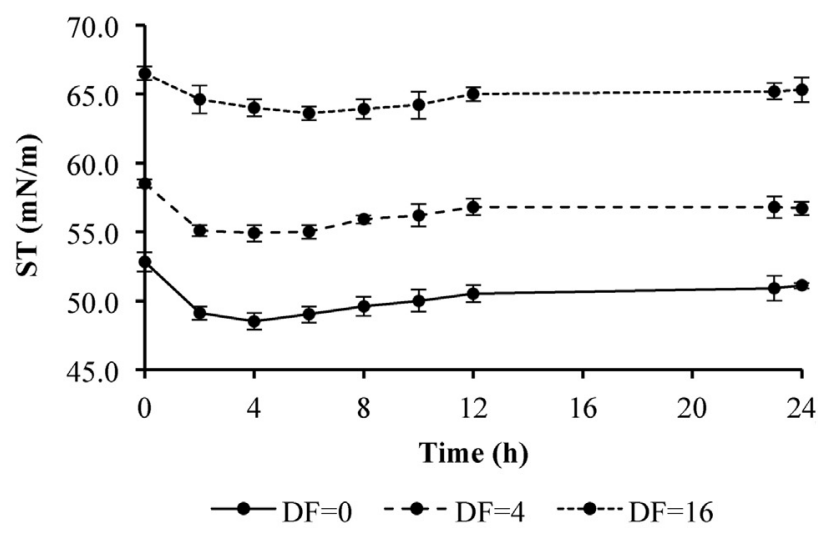

Fig. 2. Extracellular biosurfactant production by Lactobacillus paracasei grown in a culture medium containing cellulosic sugars from vineyard pruning waste (a), and in lactose-based medium (b). 
a)

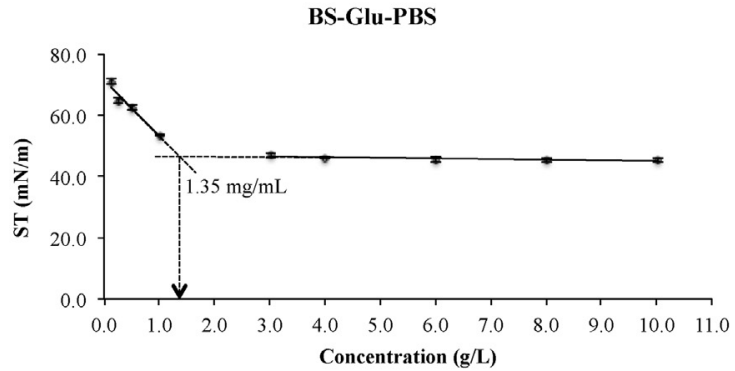

c)

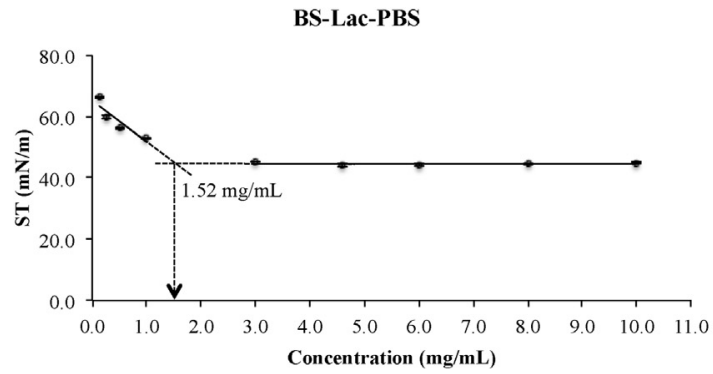

b)

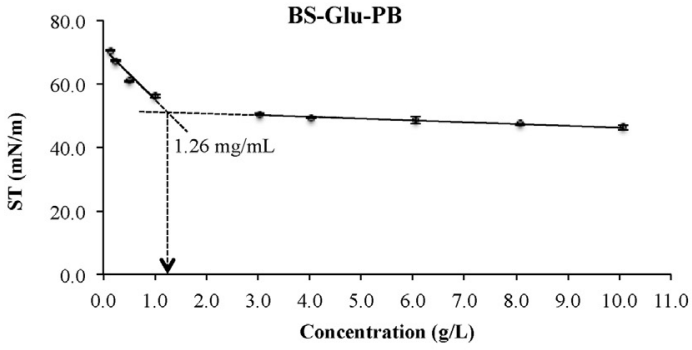

d)

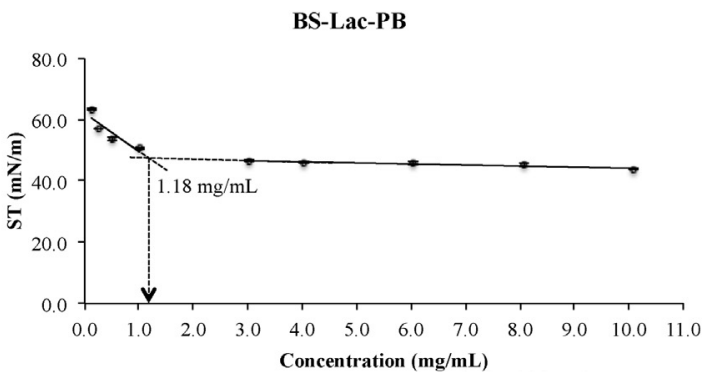

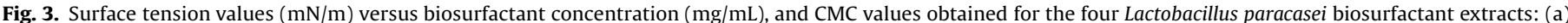

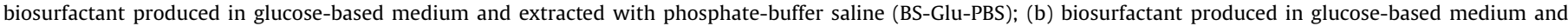

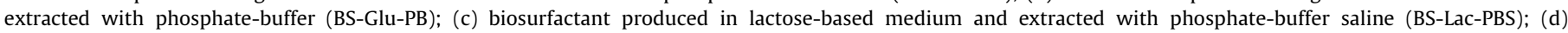
biosurfactant produced in lactose-based medium and extracted with phosphate-buffer (BS-Lac-PB).

corresponding to the biosurfactants extracted with PBS (BS-GluPBS) (Fig. 3a) and PB (BS-Glu-PB) (Fig. 3b), as well as the relationship between the biosurfactants concentration and their capacity to reduce the ST of water. It was found that, independently of the buffer used to extract the cell-bound biosurfactants, the CMC obtained was similar, being $1.35 \pm 0.13 \mathrm{mg} / \mathrm{mL}$ and $1.26 \pm 0.11 \mathrm{mg} /$ $\mathrm{mL}$ for BS-Glu-PBS and BS-Glu-PB, respectively. However, the capacity to reduce the ST of water was higher for the biosurfactant extracted with PBS $(25.1 \pm 0.49 \mathrm{mN} / \mathrm{m})$ when compared with the biosurfactant extracted with PB $(20.9 \pm 0.41 \mathrm{mN} / \mathrm{m})$. This may be due to the different composition of both biosurfactant extracts.

In a similar way, Fig. $3 \mathrm{c}$ and $3 \mathrm{~d}$ show the relationship between the concentration of biosurfactants produced by $L$. paracasei grown on lactose-based medium (extracted with PBS and PB) and their capacity to reduce the ST of water. As it can be seen, the biosurfactant extract BS-Lac-PBS exhibited the highest CMC value $(1.52 \pm 0.12 \mathrm{mg} / \mathrm{mL})$, whereas BS-Lac-PB resulted in the lowest CMC value $(1.18 \pm 0.15 \mathrm{mg} / \mathrm{mL})$. However, the biosurfactant extracted with PBS showed the highest ST reduction $(27.3 \pm 0.55 \mathrm{mN} / \mathrm{m})$, being $24.8 \pm 0.61 \mathrm{mN} / \mathrm{m}$ for the biosurfactant extracted with $\mathrm{PB}$.

The CMC values obtained in this work for the four biosurfactant extracts produced by $L$. paracasei using glucose from VPW or lactose as carbon sources, were lower than the CMC value obtained for the biosurfactant produced by the same strain using the MRSLac medium (standard MRS medium where glucose was replaced by lactose) and extracted with PBS ( $2.5 \mathrm{mg} / \mathrm{mL})$ [26]. However, a higher ST reduction $(30.2 \mathrm{mN} / \mathrm{m})$ was reported in that study.

Biosurfactants with low CMC values represent an advantage from an industrial point of view due to their higher efficiency. However, that low CMC should be accompanied by low ST values. Higher CMC values than the obtained in this work have been reported for biosurfactants produced by different Lactobacillus strains. Gudiña et al. [39] reported a CMC of $7.5 \mathrm{mg} / \mathrm{mL}$ for the cellbound biosurfactant produced by Lactobacillus agilis CCUG31450 grown in MRS medium. The biosurfactant (glycoprotein) produced by Lactobacillus plantarum CFR 2194 exhibited a CMC of $6 \mathrm{mg} / \mathrm{mL}$ [40]. Additionally, the CMC calculated for the glycolipid biosurfactant produced by Lactobacillus helveticus was $2.5 \mathrm{mg} / \mathrm{mL}$ [41]. Only the glycoprotein biosurfactant produced by Lactobacillus acidophilus RC14 exhibited a lower CMC value (1 mg/ $\mathrm{mL}$ ) when compared with the cell-bound biosurfactants herein produced by $L$. paracasei using cellulosic sugars from VPW as carbon source [42].

Moldes et al. [1] used hemicellulosic sugars from VPW as carbon source for biosurfactant production by Lactobacillus pentosus. This biosurfactant reduced the ST of water by $21 \mathrm{mN} / \mathrm{m}$. On the other hand, Portilla-Rivera et al. [5], used $L$. pentosus to produce biosurfactants from synthetically obtained hemicellulosic sugars. These biosurfactants were found to reduce the surface tension by $14-15 \mathrm{mN} / \mathrm{m}$. In conclusion, the biosurfactants produced by $L$. paracasei grown on cellulosic sugars from VPW exhibited a better surface activity when compared with those produced by $L$. pentosus grown on hemicellulosic sugars from VPW.

Characterization of $\mathrm{L}$. paracasei biosurfactants produced on different carbon sources

Regarding the biochemical characterization of the biosurfactants produced by $L$. paracasei, some differences were found in the carbohydrate, protein and lipid contents depending on the carbon source and the extraction process used (Table 1).

When $L$. paracasei was grown using glucose from VPW as carbon source, the extraction with PB led to the recovery of biosurfactants with a higher carbohydrate and protein content as compared to the ones obtained when the extraction was conducted with PBS 
Table 1

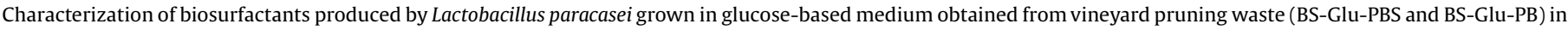
comparison with the biosurfactants produced by the same strain in lactose-based medium (BS-Lac-PBS and BS-Lac-PB).

\begin{tabular}{|c|c|c|c|c|}
\hline & BS-Glu-PBS & BS-Glu-PB & BS-Lac-PBS & BS-Lac-PB \\
\hline $\mathrm{CMC}(\mathrm{mg} / \mathrm{mL})$ & $1.35 \pm 0.13^{\mathrm{ab}}$ & $1.26 \pm 0.11^{\mathrm{ab}}$ & $1.52 \pm 0.12^{\mathrm{b}}$ & $1.18 \pm 0.15^{\mathrm{a}}$ \\
\hline ST reduction units $(\mathrm{mN} / \mathrm{m})$ & $25.1 \pm 0.49^{\mathrm{a}}$ & $20.9 \pm 0.41^{b}$ & $27.3 \pm 0.55^{c}$ & $24.8 \pm 0.61^{\mathrm{a}}$ \\
\hline \multicolumn{5}{|l|}{ Elemental analysis (\%) } \\
\hline $\mathrm{N}$ & $3.39 \pm 0.03^{a}$ & $9.32 \pm 0.50^{\mathrm{b}}$ & $5.82 \pm 0.13^{c}$ & $7.98 \pm 0.04^{\mathrm{d}}$ \\
\hline $\mathrm{C}$ & $13.83 \pm 0.16^{\mathrm{a}}$ & $35.22 \pm 2.17^{b}$ & $30.60 \pm 0.24^{c}$ & $36.69 \pm 0.19^{b}$ \\
\hline $\mathrm{H}$ & $1.96 \pm 0.10^{\mathrm{a}}$ & $3.39 \pm 0.17^{\mathrm{b}}$ & $4.74 \pm 0.02^{\mathrm{c}}$ & $5.55 \pm 0.04^{\mathrm{d}}$ \\
\hline $\mathrm{S}$ & $<0.3$ & $<0.3$ & $<0.3$ & $<0.3$ \\
\hline Total protein content (\%) & $21.19 \pm 0.18^{\mathrm{a}}$ & $58.22 \pm 3.14^{\mathrm{b}}$ & $36.09 \pm 0.40^{c}$ & $49.88 \pm 0.27^{d}$ \\
\hline Total carbohydrate content (\%) & $5.47 \pm 1.19^{\mathrm{a}}$ & $14.24 \pm 3.81^{\mathrm{b}}$ & $18.6 \pm 0.03^{\mathrm{bc}}$ & $23.3 \pm 0.05^{c}$ \\
\hline Total lipid content $(\%)$ & $24.40 \pm 1.15^{\mathrm{a}}$ & $13.66 \pm 1.22^{b}$ & ND & ND \\
\hline \multicolumn{5}{|l|}{ Major relative fatty acids (\%) } \\
\hline Myristic acid & 8.90 & 6.79 & No fatty acids present & \\
\hline Palmitic acid & 36.80 & 43.88 & & \\
\hline Palmitoleic acid & 2.82 & 4.68 & & \\
\hline Stearic acid & 35.92 & 26.11 & & \\
\hline Oleic acid & 7.44 & 1.23 & & \\
\hline Linoleic acid & 1.47 & 4.95 & & \\
\hline$\alpha$-Linoleic acid & - & 8.85 & & \\
\hline
\end{tabular}

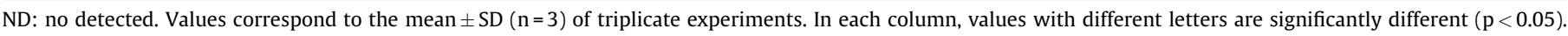

(Table 1). The same trend was found for the $\mathrm{C}$ and $\mathrm{H}$ percentages, being the biosurfactants extracted with $\mathrm{PB}$ richer in $\mathrm{C}$ and $\mathrm{H}$ than the ones extracted with PBS (Table 1 ). However, when $L$. paracasei was grown in lactose-based medium, the effect of the extraction process was almost negligible, resulting in similar percentages of $\mathrm{N}, \mathrm{C}$ and $\mathrm{H}$ for both biosurfactants.

The most important differences were observed when the lipid content and the fatty acid composition were analyzed, indicating that $L$. paracasei produced different types of biosurfactants depending on the carbon source used. When L. paracasei was grown in lactose-based medium, the biosurfactants produced contained only carbohydrates and proteins (glycoproteins). However, when it was grown on cellulosic sugars, the biosurfactants produced were a mixture of carbohydrates, lipids and proteins (glycolipopeptides).

Table 1 shows the fatty acid profile of the biosurfactants obtained using the glucose from VPW as carbon source. A high percentage of $\mathrm{C} 16$ and $\mathrm{C} 18$ fatty acids was observed, being the most abundant palmitic acid (36.8-43.9\%), followed by stearic acid (26.1-35.9\%). Furthermore, differences were observed regarding the fatty acids content depending on the extraction method used. The biosurfactants extracted with PBS contained a higher percentage of oleic acid (7.4\%), whereas $\alpha$-linoleic acid $(8.8 \%)$ was only present in those extracted with PB. Fig. 4 shows the GCMS spectra, as well as the $m / z$ spectra of the major fatty acids found in the biosurfactants produced by $L$. paracasei grown in glucosebased medium obtained from VPW.

Vecino et al. [43] reported that the biosurfactant produced by $L$. pentosus growing on hemicellulosic sugars from VPW was a glycolipopeptide, with a carbohydrate:protein:lipid ratio of 1:3:6. On the other hand, Pinto et al. [44] reported that the biosurfactant produced by the $L$. paracasei strain used in this work, grown in MRS-Lac medium (with lactose as carbon source), is a glycoprotein.

Fig. 5 shows the FTIR spectra corresponding to the biosurfactants produced by L. paracasei grown on glucose from VPW (Fig. 5a) and grown in the lactose-based medium (Fig. 5b), both extracted with PBS and PB.

The spectra corresponding to the biosurfactants produced from cellulosic sugars (Fig. 5a) indicated the presence of peptide groups (resulting from $\mathrm{O}-\mathrm{H}$ and $\mathrm{N}-\mathrm{H}$ stretching), proteins $(\mathrm{N}-\mathrm{H}$ bending) and carbohydrates ( $\mathrm{C}-\mathrm{O}$ stretching), at wavenumbers around $3400 \mathrm{~cm}^{-1}, \quad 1644 \mathrm{~cm}^{-1}$ and $1089 \mathrm{~cm}^{-1}$, respectively.
Comparing both extraction methods, the spectrum corresponding to the biosurfactant extracted with PB showed more intense bands than the ones observed in the biosurfactant extracted with PBS.

On the other hand, the spectra corresponding to the biosurfactants produced by $L$. paracasei grown in lactose-based medium and extracted with PBS or PB (Fig. 5b) did not show significant differences (i.e. bands exhibit the same intensity). However, when compared with the spectra corresponding to the biosurfactants produced from cellulosic sugars, the biosurfactants produced in lactose-based medium exhibited more intense bands in the wavenumbers around $1644 \mathrm{~cm}^{-1}$ and $1089 \mathrm{~cm}^{-1}$, which is in agreement with the differences found previously in the percentages of $\mathrm{N}$ and $\mathrm{C}$ in the elemental analysis.

These results are consistent with the FTIR data reported for the biosurfactant produced by $L$. pentosus using hemicellulosic sugars from VPW as carbon source [43].

Overall, the results herein obtained suggest that the carbon source plays an important role on biosurfactant production, which is well aligned with several previous reports. For instance, MataSandoval et al. [45] reported that the amount of rhamnolipid biosurfactant produced by Pseudomonas aeruginosa UG2 was affected by the nature of the carbon source used. The authors found that hydrophobic substrates (i.e. corn oil, lard and longchain alcohols) led to higher rhamnolipid yields when compared with hydrophilic substrates such as glucose or succinic acid. In addition, Singh et al. [46] demonstrated that Bacillus sp. strain AR2 exhibits carbon source dependence. The authors reported that when the minimal salt medium was supplemented with sucrose and glycerol, the strain produced lipopeptides as a mixture of surfactin, iturin and fengycin; however, when maltose, lactose and sorbitol were used as carbon sources, only iturin was produced.

\section{Study of the emulsifying activity of biosurfactants produced by $\mathrm{L}$.} paracasei grown on cellulosic sugars

The emulsifying activity of the biosurfactants produced by $L$. paracasei grown on glucose from VPW (BS-Glu-PBS and BS-Glu-PB) was assayed using rosemary oil as hydrophobic phase. This is the first report on the emulsifying activity of these biosurfactants.

Fig. 6 shows the macro view and the microscopic view (Fig. 6a) of oil-in-water $(\mathrm{O} / \mathrm{W})$ emulsions, as well as the relative emulsion volume (EV) and the stability of the emulsion (ES) (Fig. 6b) along 
a)

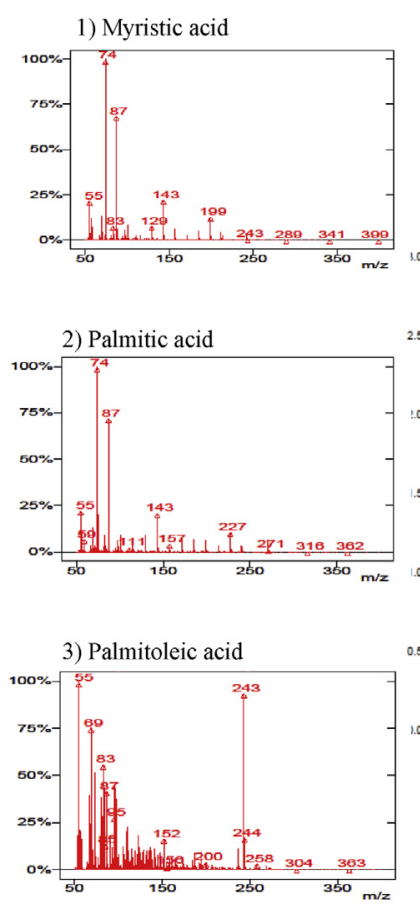

b)
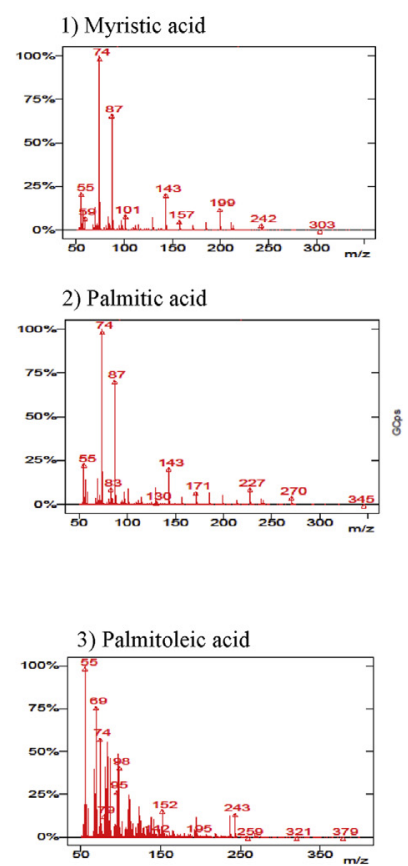
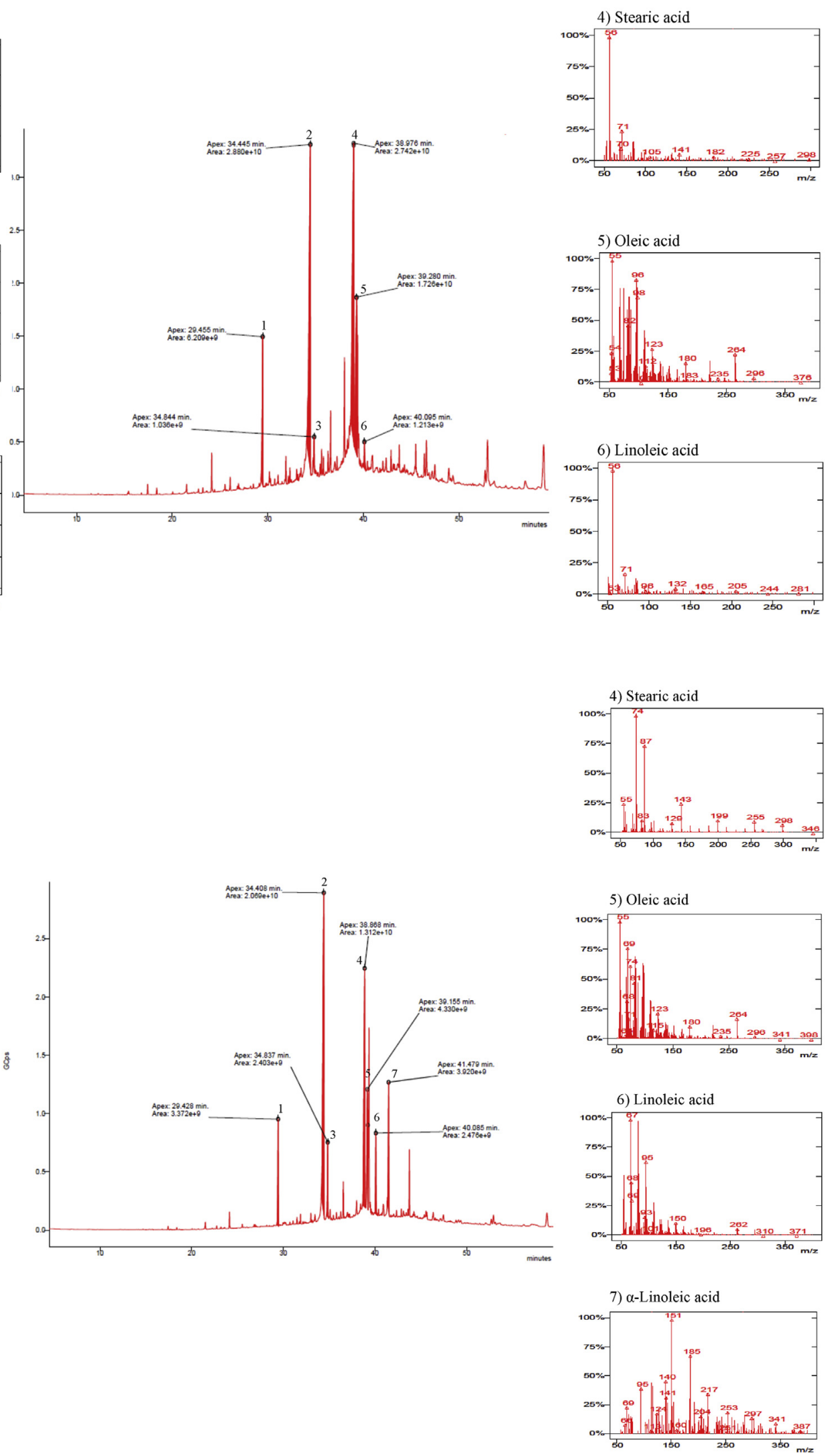

Fig. 4. GC-MS chromatograms and $m / z$ spectra of the major fatty acids present in the Lactobacillus paracasei biosurfactants: a) BS-Glu-PBS; b) BS-Glu-PB. 
a)

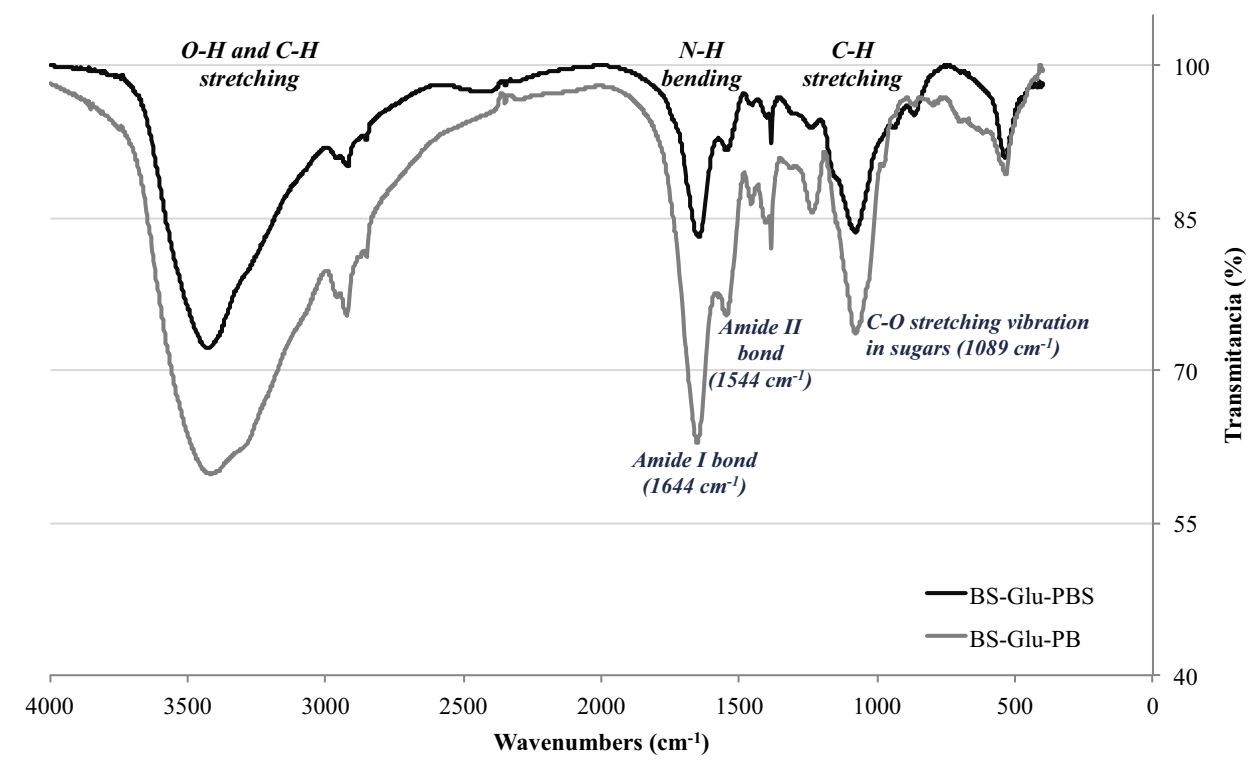

b)

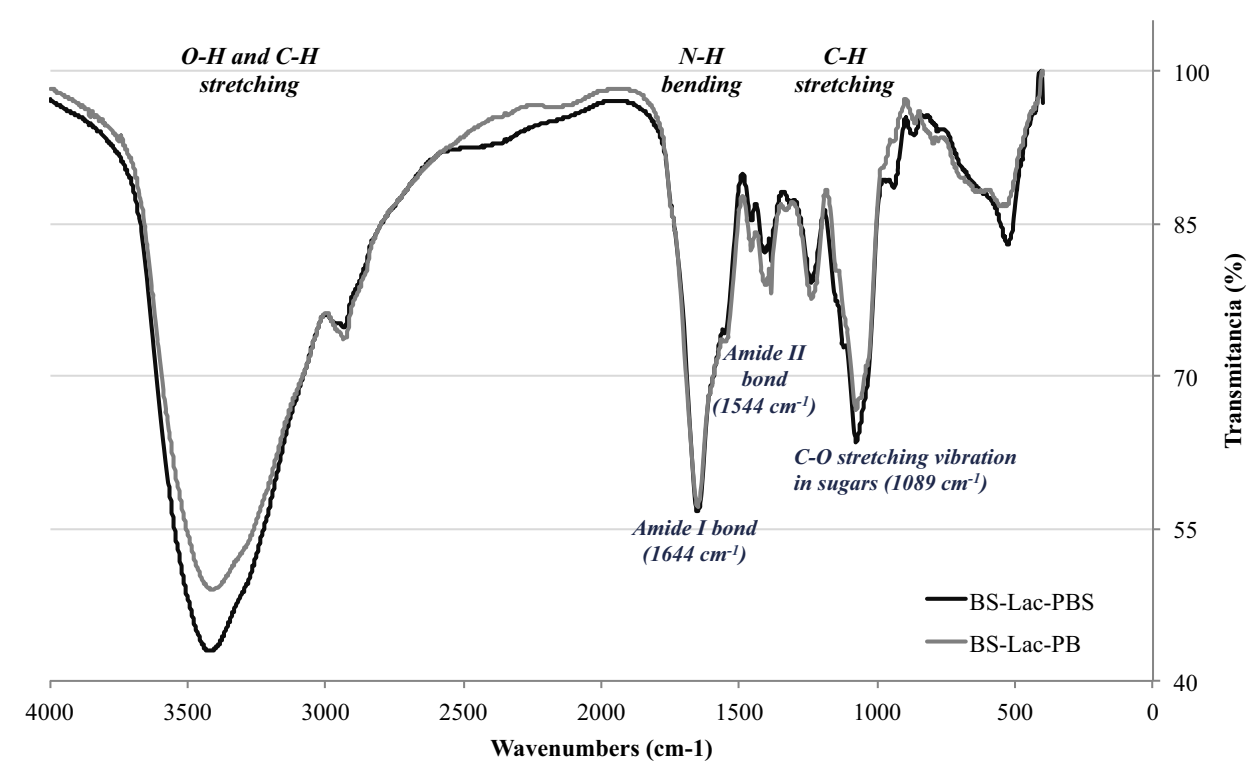

Fig. 5. FTIR spectrum of the different biosurfactants from Lactobacillus paracasei: (a) BS-Glu-PBS versus BS-Glu-PB; (b) BS-Lac-PBS versus BS-Lac-PB.

time (up to 28 days). As it can be seen in Fig. 6, the biosurfactants produced by $L$. paracasei resulted in similar EV percentages $(69.4 \%$ $71.4 \%$ ) independently of the extraction method used. However, differences were observed regarding the size of the droplets present in the emulsions stabilized with the biosurfactants obtained through the different extraction processes. The biosurfactant extracted with PB led to emulsions formed by droplets of smaller size than the ones stabilized by the biosurfactant extracted with PBS. The size of the droplets in the emulsions is an important parameter to measure their stability, as well as to define their potential applications. The results herein gathered suggest that the biosurfactant extracted with PB may be more useful for cosmetic and personal care applications, as it results in emulsions with smaller droplets, which are more suitable for these applications [23].

The results obtained regarding the emulsifying activity of the biosurfactants produced by $L$. paracasei were better when compared with those obtained using the biosurfactants produced by $L$. pentosus to stabilize rosemary oil/water emulsions. The biosurfactants were produced using hemicellulosic sugars from VPW, and the EV values obtained 24 days after the formation of the emulsion were about 55.5\% [43]. The biosurfactants herein studied exhibited also a better performance when compared with those produced by $L$. plantarum, which stabilized emulsions with 
a)
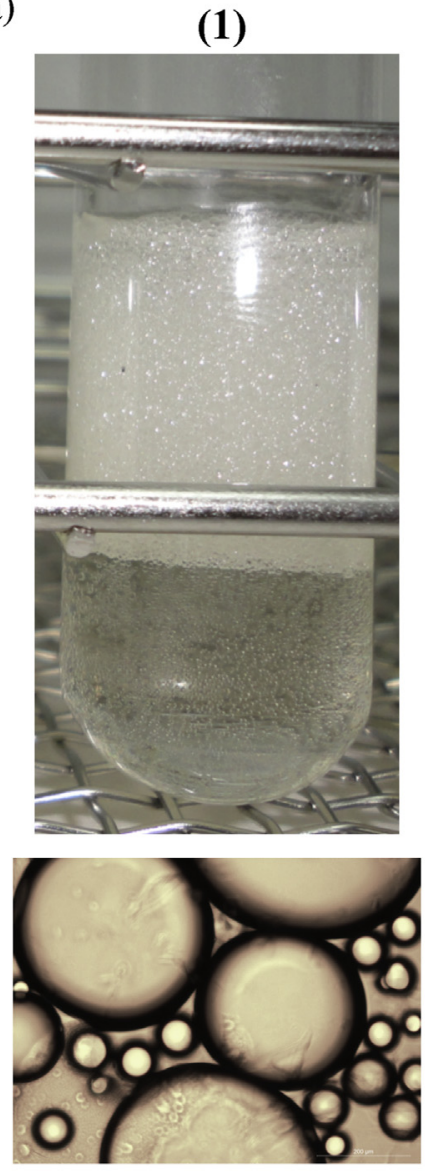

(2)
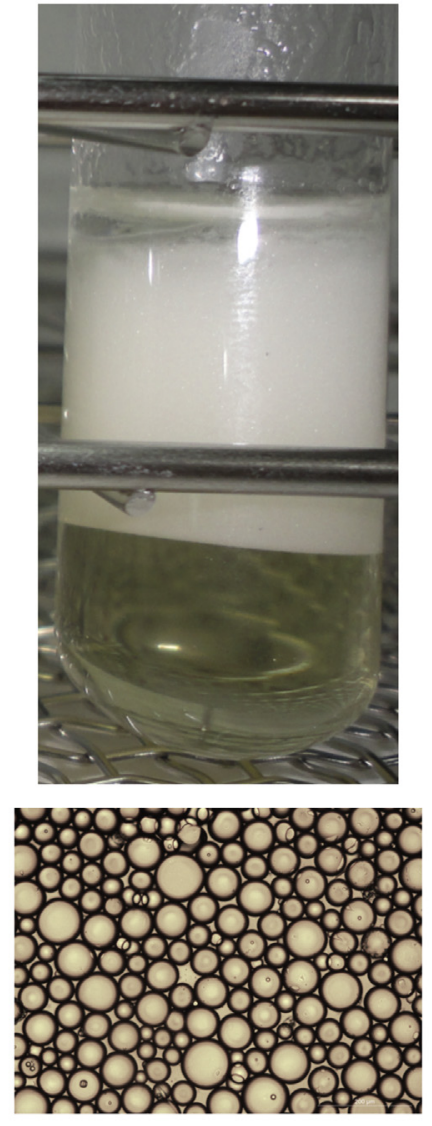

(3)
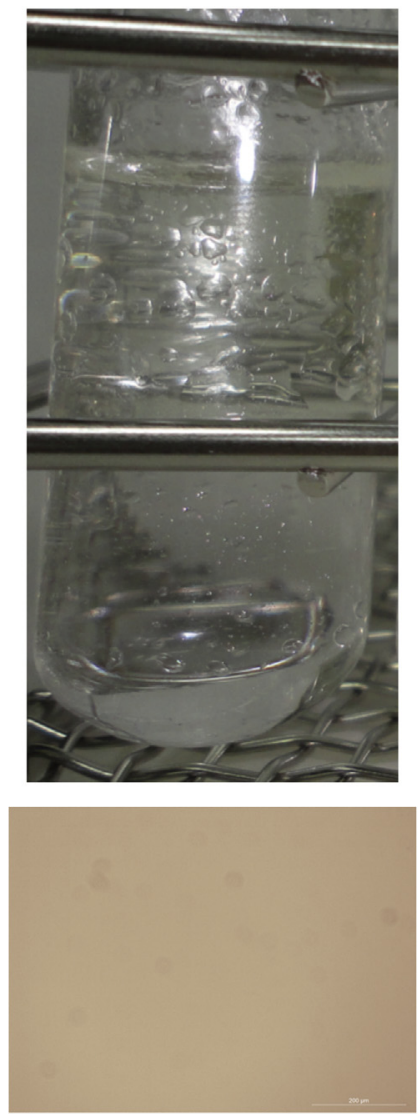

b)

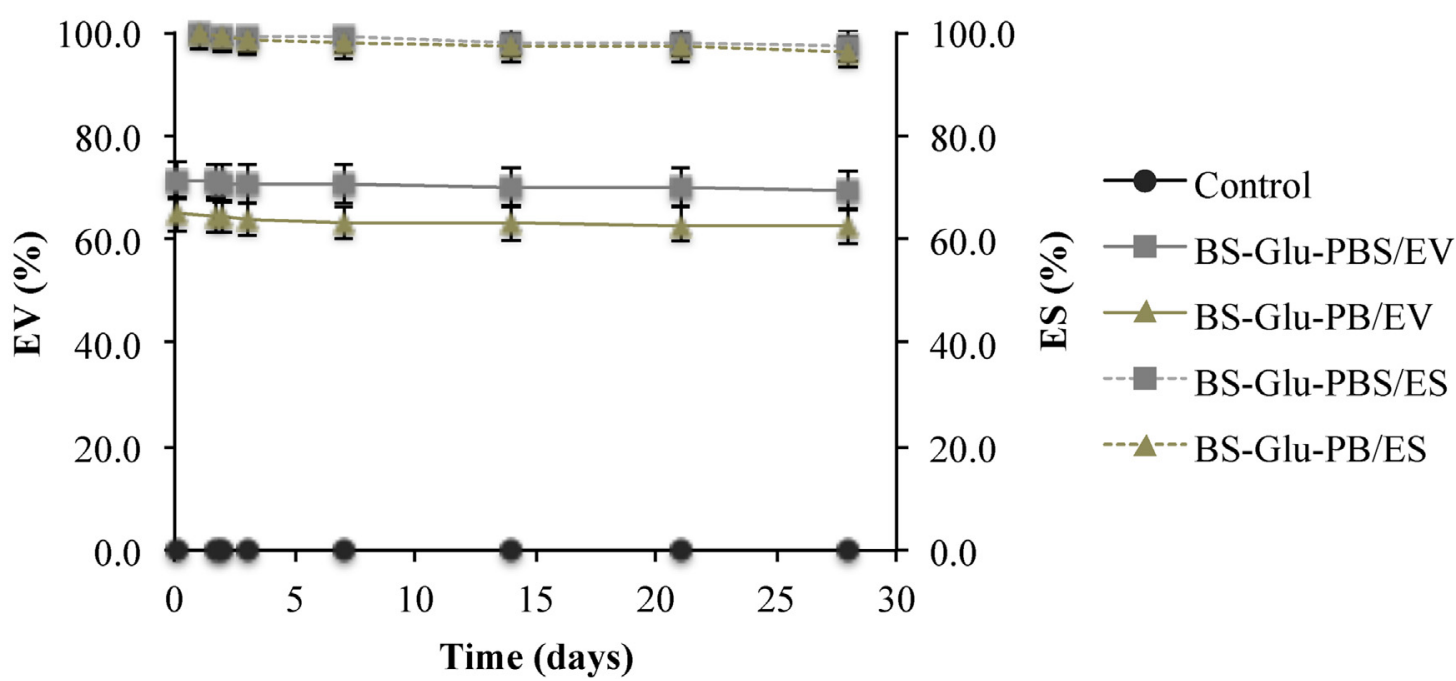

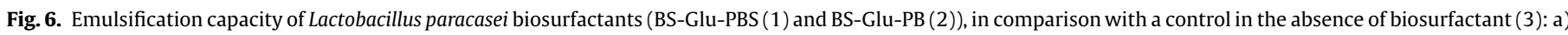

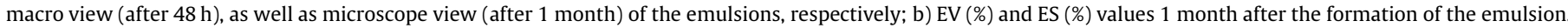
Pictures were taken with a $20 \times$ objective $(-200 \mu \mathrm{m})$. 
coconut and sunflower oils with EV values after $24 \mathrm{~h}$ of $37.9 \%$ and $19.4 \%$, respectively [40].

\section{Conclusions}

The results obtained suggest that lignocellulosic wastes could be good alternatives as low-cost carbon sources for the fermentative production of biosurfactants using $L$. paracasei. Additionally, it can be stated that the biosurfactant composition can change according to the type of carbon source and extraction process used in their production. In this case, $L$. paracasei grown on cellulosic sugars produced a glycolipopeptide biosurfactant, whereas when it was grown on lactose-based medium, the biosurfactant produced was a glycoprotein. This finding opens the door to the production of different types of biosurfactants using the same strain, by changing the carbon source and the extraction process.

\section{Acknowledgements}

This study was supported by the Portuguese Foundation for Science and Technology (FCT) under the scope of the strategic funding of UID/BIO/04469/2013 unit, COMPETE 2020 (POCI-010145-FEDER-006684) and the project RECI/BBB-EBI/0179/2012 (FCOMP-01-0124-FEDER-027462), as well as X. Vecino postdoctoral grant (SFRH/BPD/101476/2014). The authors also acknowledge financial support from BioTecNorte operation (NORTE01-0145-FEDER-000004) and the project MultiBiorefinery (POCI01-0145-FEDER-016403) funded by the European Regional Development Fund under the scope of Norte2020-Programa Operacional Regional do Norte and the Post-doctoral grant CEB-BPD/01/ 2015/07 from the project UID/BIO/04469/2013, funded by FCT, to E. Gudiña. Additionally, the authors acknowledge the financial support from Spanish Ministry of Economy and Competitiveness (FEDER funds under the project CTM2015-68904) and L. Rodríguez-López acknowledges to the Spanish Ministry of Education, Culture and Sport for her pre-doctoral fellowship (FPU15/00205).

\section{References}

[1] A.B. Moldes, A.M. Torrado, M.T. Barral, J.M. Domínguez, J. Agric. Food. Chem. 55 (2007) 4481

[2] R. Devesa-Rey, X. Vecino, J.L. Varela-Alende, M.T. Barral, J.M. Cruz, A.B. Moldes, Waste Manage. 31 (2011) 2327.

[3] J.M. Aurand, B. Iasiello, V. Magalhaes, P. Aigrain, OIV Vine and Wine Outlook, OIV - 18, rue d'Aguesseau - F 75008, Paris, 2012 ISBN 979-10-91799-56-0.

[4] G. Bustos, N. de la Torre, A.B. Moldes, J.M. Cruz, J.M. Domínguez, J. Food Eng. 78 (2007) 405

[5] O.M. Portilla-Rivera, A. Torrado-Agrasar, J. Carballo, J.M. Domínguez, A.B Moldes, J. Agric. Food. Chem. 57 (2009) 9057.

[6] N. Rodríguez, A. Torrado, S. Cortés, J.M. Domínguez, J. Sci. Food Agric. 90 (2010) 1726 .
[7] X. Vecino, R. Devesa-Rey, J.M. Cruz, A.B. Moldes, J. Agric. Food. Chem. 60 (2012) 1258.

[8] S. Cortés-Camargo, N. Pérez-Rodríguez, R.P.D.S. Oliveira, B.E.B. Huerta, J.M. Domínguez, Ind. Crops Prod. 79 (2016) 258.

[9] G. Bustos, A.B. Moldes, J.M. Cruz, J.M. Domínguez, J. Sci. Food Agric. 84 (2004) 2105.

[10] A.B. Moldes, A. Torrado, A. Converti, J.M. Domínguez, Appl. Biochem. Biotechnol. 135 (2006) 219.

[11] A.B. Moldes, G. Bustos, A. Torrado, J.M. Domínguez, Appl. Biochem. Biotechnol. 143 (2007) 244.

[12] B. Rivas, A. Torrado, S. Rivas, A.B. Moldes, J.M. Domínguez, J. Sci. Food Agric. 87 (2007) 1603.

[13] O.M. Portilla, B. Rivas, A. Torrado, A.B. Moldes, J.M. Domínguez, J. Sci. Food Agric. 88 (2008) 2298.

[14] C. García-Diéguez, J.M. Salgado, E. Roca, J.M. Domínguez, Bioprocess Biosyst. Eng. 34 (2011) 869.

[15] B. Max, J.M. Salgado, S. Cortés, J.M. Domínguez, J. Agric. Food. Chem. 58 (2010) 1909.

[16] N. Rodríguez-Pazo, J.M. Salgado, S. Cortés-Diéguez, J.M. Domínguez, Appl. Biochem. Biotechnol. 169 (2013) 2175.

[17] G. Bustos, A.B. Moldes, J.M. Cruz, J.M. Domínguez, J. Sci. Food Agric. 85 (2005) 466.

[18] X. Vecino, R. Devesa-Rey, A.B. Moldes, J.M. Cruz, Chemosphere 111 (2014) 24.

[19] X. Vecino, R. Devesa-Rey, J.M. Cruz, A.B. Moldes, Carbohydr. Polym. 115 (2015) 129.

[20] R. Marchant, I.M. Banat, Biotechnol. Lett. 34 (2012) 1597.

[21] E.J. Gudiña, V. Rangarajan, R. Sen, L.R. Rodrigues, Trends Pharmacol. Sci. 34 (2013) 667.

[22] E.J. Gudiña, J.A. Teixeira, L.R. Rodrigues, Mar. Drugs 14 (2016) 1.

[23] X. Vecino, J.M. Cruz, A.B. Moldes, L.R. Rodrigues, Crit. Rev. Biotechnol. (2017) 1.

[24] R.S. Makkar, S.S. Cameotra, I.M. Banat, AMB Express 1 (2011) 1.

[25] E.J. Gudiña, A.I. Rodrigues, V. de Freitas, Z. Azevedo, J.A. Teixeira, L.R. Rodrigues, Bioresour. Technol. 212 (2016) 144.

[26] E.J. Gudiña, J.A. Teixeira, L.R. Rodrigues, Colloid Surf. B 76 (2010) 298.

[27] J.M. Cruz, A.B. Moldes, G. Bustos, A. Torrado, J.M. Domínguez, J. Sci. Food Agric. 87 (2007) 1000.

[28] M. Mandels, R. Andreotti, C. Roche, Biotechnol. Bioeng. Symp. 6 (1976) 21.

[29] M. Paquot, P.H. Thonart, Holzforschung 36 (1982) 177.

[30] E.J. Gudiña, J.A. Teixeira, L.R. Rodrigues, Appl. Environ. Soil Sci. (2011) 1.

[31] X. Vecino, G. Bustos, R. Devesa-Rey, J.M. Cruz, A.B. Moldes, J. Surfactants Deterg. 18 (2015) 267.

[32] S. Kim, E. Lim, S. Lee, J. Lee, T. Lee, Biotechnol. Appl. Biochem. 31 (2000) 249.

[33] M. Dubois, K.A. Gilles, J.K. Hamilton, P.A. Rebers, F. Smith, Anal. Chem. 28 (1956) 350.

[34] F. Mariotti, D. Tomé, P.P. Mirand, Crit. Rev. Food Sci. 48 (2008) 177.

[35] J.M. Folch, M. Lees, H.S. Stanly, J. Biol. Chem. 226 (1956) 497.

[36] L. Rodríguez-López, X. Vecino, L. Barbosa-Pereira, A.B. Moldes, J.M. Cruz, Food Funct. 7 (2016) 3724.

[37] M. Das, S.K. Das, R.K. Mukherjee, Bioresour. Technol. 63 (1998) 231.

[38] L. Rodrigues, A. Moldes, J. Teixeira, R. Oliveira, Biochem. Eng. J. 28 (2006) 109.

[39] E.J. Gudiña, E.C. Fernandes, J.A. Teixeira, L.R. Rodrigues, RSC Adv. 5 (2015) 90960.

[40] A.N. Madhu, S.G. Prapulla, Appl. Biochem. Biotechnol. 172 (2014) 1777.

[41] D. Sharma, B.S. Saharan, N. Chauhan, A. Bansal, S. Procha, Sci. World J. (2014) 1.

[42] M.M.C. Velraeds, H.C. Van Der Mei, G. Reid, H.J. Busscher, Colloid Surf. B 8 (1996) 51.

[43] X. Vecino, L. Barbosa-Pereira, R. Devesa-Rey, J.M. Cruz, A.B. Moldes, J. Sci. Food Agric. 9 (2015) 313.

[44] S. Pinto, P. Alves, A.C. Santos, C.M. Matos, B. Oliveiros, S. Gonçalves, E. Gudiña, L. R. Rodrigues, J.A. Teixeira, M.H. Gil, J. Biomed. Mater. Res. Part A 98 (2011) 535

[45] J.C. Mata-Sandoval, J. Karns, A. Torrents, Microbiol. Res. 155 (2001) 249.

[46] A.K. Singh, R. Rautela, S.S. Cameotra, Microb. Cell Fact. 13 (2014) 2. 